\title{
Conceptions of Musical Understanding
}

\author{
Susan Hallam \\ Institute of Education, United Kingdom
}

\section{IouliaPapageorgi}

University of Nicosia, Cyprus

\begin{abstract}
Music can be understood in many ways. This has important implications for music education. The research reported here explored how groups of people conceptualise musical understanding and what they believe supports its acquisition. In this study 465participants completed two statements: 'Musical understanding is' and 'You learn to understand music through'. Understanding music was viewed as complex and multidimensionalwith two overarching themes: personal musical understanding in context and understanding as process, with ten main sub-themes of understanding: communication, kinaesthetic, emotional, personal, knowledge about music, critical evaluation,musical elements, analysis and comparison of music, internal representations, and creating music.Understanding was believed to be acquired through love and enjoyment of music, physical responses, emotional engagement, analytic processes, active engagement with music, education or guidance in formal or informal contexts, exposure to music, and listening. A model is set out illustrating the different ways in which it is possible to understand music and how these various understandings can be attained and supported.
\end{abstract}




\section{Keywords}

development, expertise, learning, music, understanding

\section{Introduction}

Research on human understanding has tended to focus either on what it means to understand and how understanding develops or on the way that knowledge is constructed.In education, the work of Piaget (1973) and Vygotsky (1978) has been particularly influential in addressing issues relating to how we learn and understand, both arguing that learning depends on experience, although Piaget emphasized the individual's interaction with the environment, while Vygotsky stressed the importance of social interaction. Their work has been taken forward by many authors notably Bruner (1966), Rogoff (1990), Wenger (1998) and Wertsch(1985) who have set out ways in which the work of Piaget and Vygotsky could be applied in education. Related research has focused on developing taxonomies of learning outcomes concerning levels of understanding (e.g. Bloom, 1956; Gagne, 1985; Biggs, 1979).

A parallel strand of research has focused on the construction of knowledge. Cognitive psychologists have proposed schema theory where a schema is a mental structure, whichorganises andcategorisesinformation and the relationships between different information (Anderson, 1984), while linguists and psycholinguists have focused on conceptual metaphorwhich refers to the understanding of one idea, or conceptual domain, in terms of another(Lakoff\& Johnson, 2003). These approaches both argue that understanding is constructed from life experiences. This is supported by evidence from neuroscience which has shown how the brain changes in response to individual experience leading to the brain substrates of processing reflecting the "learning biography" of each individual (Altenmuller, 2003, p. 349). 
What these various approaches have in common is that they all propose that knowledge is constructed by individuals on the basis of their experiences. Taking this as its starting point, the aim of the research reported here was to explore how individuals with different levels of experience with making musicconceptualise the nature of musical understanding.

\section{Conceptions of Musical Understanding}

Developing insights into the ways that people understand music has important implications for the development of the music curriculum in formal education and the provision of musical activities in the wider community. The understanding of music can be viewed from a range of different perspectives: philosophical, sociological, psychological, biological, neurological, mathematical, musicological, aesthetic, and educational. Over thousands of yearsefforts have been made to study the significance of musical experience for human perception, its relationship with the natural world and its political and social impact. Over time our understanding has increased but there has been a lack of coherence between the different conceptualizations. As Fiske (2008) puts it:

Giventhe immense research effort, one might expect that we would, by now, know far more about musical understanding than we do. Indeed we do know a great deal about the acoustics of music, essential auditory processing protocols, music's emotional impact, the various ways in which music can be effectively used in social rituals or entertainment, and the rules of various musical grammars. But these stories seem incomplete and often disconnected from each other. Our understanding of one of humanity's most unique traits remains in many ways as elusive as it was to scholars thousands of years ago. (p iii) 
This lack of a coherent conception of what constitutes musical understanding has led to considerable controversy and debate. This presents a particular problem for music education,as it might legitimately be expected that teachers would have a shared conceptualisation of what it means to 'understand' music.This lack of consensus may explain why issues relating to musical understanding are rarely made explicit in education.

\section{Understanding as Musical Cognition}

Early research on musical understanding approached it taking a cognitive perspective. For instance, Seashore (1919) was concerned with understanding the complex structure of musical processes and the systematic structures underpinning understanding. He viewed the musical mind as perceiving and apprehending the attributes of sound (pitch intensity, duration and extensity) and identified the importance of the representation of music in memory and thought as fundamental to musical understanding. Mursell (1937) proposed that learners needed to attend to a broad range of musical elements and the way that these createda musical entity in complex ways. Mursell identified specific musical elements that he believed became the listeners' focus,thus determining understanding. The lowest level was a focus on shifting dynamics and qualities of tone with no awareness of structure or design. At a slightly higher level was the sequencing of tonal patterns into melodies, followed by rhythm, harmony and finally, 'the general architectonicdesign of the music (p. 215).These early conceptions which highlighted the role of musical perception as the basis for understanding music had limited relevance in terms of music education as research began to show that the fundamental processes for music perception were present from birth.Infants are predisposed to attend to melodic contour, rhythmic patterning and consonant sounds and are similar to adults in their sensitivity to the pitch and rhythmic grouping of sounds. What they lack is the complex skills required for the perception of music 
from any particular culture. It became clear that understanding of tonality was not innate and that infants needed to learn the particular tonal systems of their culture and that this process took time. In western cultures by one year old infants respond differently to diatonic and non-diatonic patterns and by three or four display the ability to respond to the degree of tonality of the stimuli (Dowling, 1988). Depending on their musical environment, by the age of five children can generally organise songs around stable tonal keys although they do not have a stable tonal scale system that can be used to transpose melodies. This develops later (Lamont \& Cross, 1994) and depends on the type and extent of exposure to music of any particular child. Memory for music is crucial to its reproduction. Implicit knowledge of tonal systems provides a framework which facilitates this. By 12 months infants have become accustomed to the musical conventions, patterns and structures of the music that surround them and prefer patterns that conform to that structure (Trehub, Hill, \&Kamenetsky, 1997).Pre-school children can recognise familiar tunes across many different types of transformations. Overall, the evidence suggested that infants are sophisticated listeners to music and can remember complex pieces of music in long-term memory (Trehub et al., 1997).

Given these sophisticated systems for processing sound,musical understanding began to be conceptualized in different ways. Gordon (1993), whose main focus was assessing musical potential,proposed that to understand music,learners should be able to audiate, i.e. hear and comprehend music for which sound is no longer or may never have been physically present (1993, p. 13). This approach has proved to be highly controversialand criticized,in part because it has been seen as too atomistic,but also because audiationhas been argued as not being necessary for understanding (e.g. Colwell \& Abrahams, 1991; Woodford, 1996). 
Serafine (1988) defined musical understanding as thinking in or with sound, whichoccurred when individuals could distinguish global features such as dynamics, mood, rhythm, pulse, timbre, and musical structure. While she recognised that these terms were necessary to communicate about music she argued that their use did not constitute musical understanding. She emphasized that music's organization in an ongoing temporal context distinguished it from other artistic domains and mere sound. For her, musical understanding was constructed. Dowling (1999) explored how understanding developed over time, arguing that musical understanding required sub-conscious analysis relating it to the processing of language, whileLipscomb (1996) proposed the term 'apperception' to describe the acquisition, storage, retrieval and use of knowledge obtained through the senses and perceptual systems. He argued that for musical understanding to be achieved, music must be stored in memory in a different form from its acoustical properties. As music is listened to,attention is given to different elements. This process is guided by pre-existing knowledge of structure and schemata developed through past experience. As these processes occur as the result of natural exposure to music, a key question emerges in relation to what understandings should be addressed in the context of music education.

\section{Aesthetic Understanding}

Aesthetic understanding extends the notion of musical perception as understanding to include the taste and judgment of each listener. It goes beyond mere perception and requires involvement, perception of interacting events within the music, cognition of the interplay among the events within the music and an emotional reaction of some kind (Knieter, 1971; Reimer, 1970). Aesthetic experience is distinguished from affective experience in that it goes beyond emotional responses requiring active reflection. There is considerable debate as to what makes some 
interactions aesthetic and others not. Some have argued that the term aesthetic experience can be applied to reaction to any work of art including the response of a young person to the latest pop release (Hargreaves, 1986).

\section{Physiological and Emotional Responses to Music}

Music can produce a wide range of physiological responses (Bartlett, 1996). Although there are no clear patterns between particular types of music and specific physiological measures, broadly, exciting music leads to increased arousal, calming music the reverse. However, individual cognitive responses to music may mediate physiological responses explaining some of the variability in findings (Ogata, 1995; Vanderark\& Ely, 1993). Individual responses may also depend on how often individuals listen to music, whether they are musically trained, whether they like the kind of music played, how they interpret the music, their personality and their typical level of physiological arousal(LeBlanc, 1982). Physiological responses can lead to behavioural changes. For instance, when lively music is playing,young children become more active(Ferguson et al., 1994). There is also evidence that muscular tension can be reduced by listening to quiet, sedative music (Bartlett, 1996).

As music has become more easily accessible it has become evident that individuals have considerable understanding of the impact of music on their moods and emotions and not only use music to manipulate their own moods but to create environments that will influence the moods of others (e.g. DeNora, 2000; Sloboda, O’Neill, \&Ivaldi, 2001; Sloboda\&O’Neill, 2002). Young people also perceive music as a means for mood regulation, especially for controlling their feelings and making them feel good (North et al., 2000; Saarikallio\&Erkkila, 2007). Music can evoke very strong emotional experiences (see Gabrielsson, 2001 for a review) and can be used to overcome powerful emotions. This may explain why adolescents who report a high frequency of 
personal problems listen to music more frequently than their peers (Behne, 1997). Knowledge about how music affects moods and emotions seems to develop naturally in the same way as musical perception.

Physical and emotional responses to musiccan be explained in several ways. There may be 'prewired' connections between musical stimuli and emotional responses, particularly in relation to the "primitive" components of music, e.g. loudness, timbre, pitch and tempo (Gabrielsson, 1993). Cognition may also play a mediating role; for instance, a particular piece of music might be connected with an emotional event. Alternatively, emotion may be aroused when musical expectations are disconfirmed or delayed (Meyer, 1956). It is likely that all three explanations are relevant on different occasionsor working in combination.

The role of emotion has been acknowledged by some authors theorizing musical understanding. Seashore (1919) observed that thought was inseparable from feeling and action, while Mursell (1937) argued that music carries emotion without representation or symbolism. For him, listening was the primary musical activity but what was perceived was 'constructed' by individuals, as everyone brings their previous experiences to the listening process. Elliott (1995) in his 'praxial' philosophy of music suggested that musical understanding is based on a cognitive-affective constructive process. He suggested that music is expressive of specific emotions which 'provide the artistic means to extend the range of our expressive powers beyond those we find naturally and ordinarily' (Elliott, 2005, 97). Bartel (2002) also supported the view that emotion is an important part of musical understanding and argued that 'the biggest lack in theories of musical understanding is the absence of a thorough integration of emotional tone into every construct' (p 65). 


\section{The Complexity of Musical Understanding}

Several authors have proposed that musical understanding can operate at different levels and can be partial and a matter of degree (e.g. Budd, 1985; Tanner, 1985; Davies, 1994). Elliott (1995) spoke of musical knowing rather than understanding and suggested that this could be formal, informal, impressionistic, supervisory and procedural, while Zenker (2002) proposedthat there is no single 'music-understanding-know-how' and that musical understanding depends on engagement in a wide variety of musical activities.

Some have focused on understanding as application. For instance, Gardner (1999) suggestedthat an 'individual understands a concept, skill, theory, or domain of knowledge to the extent that he or she can apply it appropriately in a new situation' (p. 119). Swanwick and Tillman (1986) demonstrated how understanding developed practically through studying the process of children and young people's composing. On the basis of their findings theydevised a descriptive spiral building on the ideas of mastery, imitation, imaginative play and metacognitionwith understanding moving through sensory, manipulative, personal expressiveness, vernacular, speculative, idiomatic, symbolic, and systematic phases. The importance of musical engagement is reinforced with Swanwick and Franca (1999) arguing that musical understanding is 'an underlying conceptual dimension that is manifested through the various channels - composing, performing and audience-listening' ( $\mathrm{p}$ 12). Overall, there is recognition that musical understanding differs at the individual level (e.g. Glover 1990; Haack, 1990) and is shaped by the extent of engagement with music (e.g. Burnard, 2000; Campbell, 1998; Davidson et al., 1988), the context of that engagement (e.g. Dibben, 2001) and the culture within which is embedded (e.g. Campbell, 2005; Dibben, 2001). 


\begin{abstract}
Aims of the Current Research
Music education over the years has variously focused on the perceptual aspects of music (being able to recognize different instruments, rhythms, melodic and harmonic structures and forms); knowledge about music and its context; aesthetic appreciation; and the application of skills through re-creating or creating music. Overall, there has been less attention to understanding music through its affective impact despite the increasing evidence that this may be how it is most frequently appreciated in everyday life. This begs the question as to how music is understood by those who are not music educators; for instance, do adults and children have different conceptions of what it means to understand music, or are there differences between people with different levels of musical expertise?This paper addresses these questions,reporting the findings of a research project exploring how different groups of people conceptualise musical understanding and what they believe enables individuals to acquire it. The research questions were:

_ in what ways do people conceptualise musical understanding?

— are there differences in conceptualization between adults and children with different levels of musical expertise?

- how do people believe that musical understanding is acquired?

— are there differences in beliefs about how musical understanding is acquired between adults and children with different levels of musical expertise?
\end{abstract}

\title{
Methodology
}

In order to address these questions, 465 individuals comprising 113 adult professional musicians, 60adult amateur musicians, 94 adult non-musicians, 92school students actively engaged in extra-curricular musical activities and 104 students only engaged in music making as part of the 
school curriculumwere asked to complete two statements 'Musical understanding is' and 'You learn to understand music through'. Open ended statements were used to make it possible to access people's deeply held views rather than using statements with which they could agree or disagree, which may have inclined them to respond in particular ways.

The sample was derived from children in two secondary schools; those participating in extra curricula musical activities in Local Authority Music Schools; adults participating in amateur choirs, bands and orchestras; professional musicians who engaged in freelance performing activities and taught instruments and class music lessons; and other members of the public accessed through a snowballing technique who had no active engagement with making music, although they may have listened to it on a regular basis. The research followed the ethical guidelines of the British Educational Research Association. Participants provided no personal information in responding to the questions beyond their membership of one of the above groups;anonymity was therefore assured. All participation was voluntary. The qualitative data were analysed through an iterative process outlined by Cooper and McIntyre (1993). The responses were coded into themes using an iterative process described by Tesch (1990) as empirical phenomenology since it treats the participants' accounts and thoughts about their own experience as data. The process involved:

1. Reading a random sample of responses;

2. Identifying points of similarity and difference among these responses in relation to the research questions;

3. Generating theories against a new set of responses;

4. Testing theories against a new set of responses;

5. Testing new theories against responses that had already been dealt with; 
6. Carrying all existing theories forward to new responses;

7. Repeating the above process until all data had been examined and all theories tested against all data (Cooper \&McIntyre, 1993).

NVivo was utilized to facilitate the process. A range of themes emerged which are described below.

\section{Findings}

\section{Conceptions of Musical Understanding}

A number of respondents made statements which merely stated that understanding music was understanding music, for instance:

'Knowing how to play and understand the true meaning of music.'

'Someone who has musical understanding is a person who understands music. '

A number indicated that it was very difficult to define or that they would not use the term 'understanding' to describe meaning in music:

'That is a big question.'

I've never been sure what the phrase musical understanding means'

'Maybe musical understanding is undefinable in words.'

Many of the respondents indicated that understanding music was complex and multidimensional and that music could be understood in many different ways:

'A peculiar but highly satisfying conjunction of intellectual appreciation (of form) and of emotional response (to sound).'

'A whole network of different cognitive, psychological, sociological, musicological as well as neuropsychological processes.' 
In addition to this acknowledgement of complexity two overarching themes emerged from the data, personal understanding in context and understanding as part of the process of engagement with music. In relation to understanding as the process of active engagement with music five key sub-themes emerged: creating music; analysis/comparison; kinaesthetic understanding; critical evaluation; and internal representations of music. Personal understanding in context included understanding music as a form of communication, emotional understanding, personal understandings, knowledge about music, and understanding musical elements. Some of these sub-themes also had itemised sub-categories. These are set out in Tables 1 and 2 with examples of quotations from each theme and sub-theme.

\section{Table 1: Themes emerging in relation to personal musical understanding in context}

\section{Personal understanding in context}

Understanding music as a form of communication

Music as a language

'To know the language of any type of music and be able to interpret it.'

'The ability to comprehend music as an expressive language by means of awareness and knowledge obtained through listening.'

\section{Understanding the composers intentions}

'Understanding what the composer wants to express through the song or the classical piece they have composed.'

'Understand the message or feeling that the composer artist is trying to convey'

'Understand the words'

'It means when you understand the music - what it's trying to tell you about.'

\section{Understanding sound}

'How sound is recorded, transmitted, and received by the listener. Acoustics, distortion, echo and other effects'

\section{Emotional understanding}

'Experiencing feelings in response to the music.'

'Being able to understand the emotions that are being conveyed and to derive joy and understanding.'

'Hearing music and being moved emotionally or subconsciously by it for no academic or definable reason.'

'Musical understanding occurs when the music communicates its intention to the listener and the listener experiences an emotional or even spiritual experience.'

'Bypassing language and cultural norms to make contact with emotions directly.'

\section{Personal meanings}

Personal/subjective understanding

'Being able to produce yourself what you believe the music to mean. It's a personal relationship with the page/aural stimulus.'

'Musical understanding is highly subjective. I would argue that there is no absolute musical understanding but that each individual makes their own understanding of a particular piece of music.' 


\section{Links with other elements of life}

'The subtleties of music escape me. Nevertheless some performances of some pieces of music do affect my feelings. Some move me considerably, usually, I suspect by associations with the first time I heard them or some other emotional event in my life.'

'Listening to the lyrics and try to link it to everyday life'

Subjective appreciative evaluation

'A simple understanding of what you like.'

'Having an opinion/musical taste.'

\section{Knowledge about music}

Knowledge of factual or historical aspects of music

'Knowledge of music, composers, history, background.'

'Knowledge of the era in which the music was written and why that kind of music was popular.

Being able to place it in a particular historical and cultural context.'

Knowledge of genre

'Having a thorough knowledge of various musical genres.'

'There is also the notion of having a wide knowledge of different genres of music, of different musicians within a genre. Someone might have a wide knowledge of jazz which enables them to identify different styles within jazz.'

\section{Knowledge of cultural context}

'Understanding cultural attitudes in society.'

'Initially understanding is a form of tacit knowledge of musical practices as heard/experienced within the historically specific, socio-cultural milieu of a person's childhood.'

\section{The role and function of music in culture}

'The place in human society, its uses in society, its impact on society economically, politically, scientifically, religiously as a force and agent for change.'

'Understanding how music has been constructed in the past and for what purpose.'

\section{Understanding musical elements}

'Being able to listen to music with perception of melody, harmony, rhythm and timbre.'

'An awareness and appreciation of how music communicates through rhythm, pitch, speed, volume, and instrumental and vocal tone, and colour.'

\section{Musical structure}

'Understanding the structure of music, the way in which tones and rhythms are constructed and manipulated to produce certain effects.'

'A sense of the structure of a piece, its harmony, melodic structure and form.'

Identifying instrumentation

'The knowledgeable listener knows which instruments are playing.'

'Distinguish the instruments which are used in music.' 
Table 2: Themes emerging in relation to musical understanding in terms of process

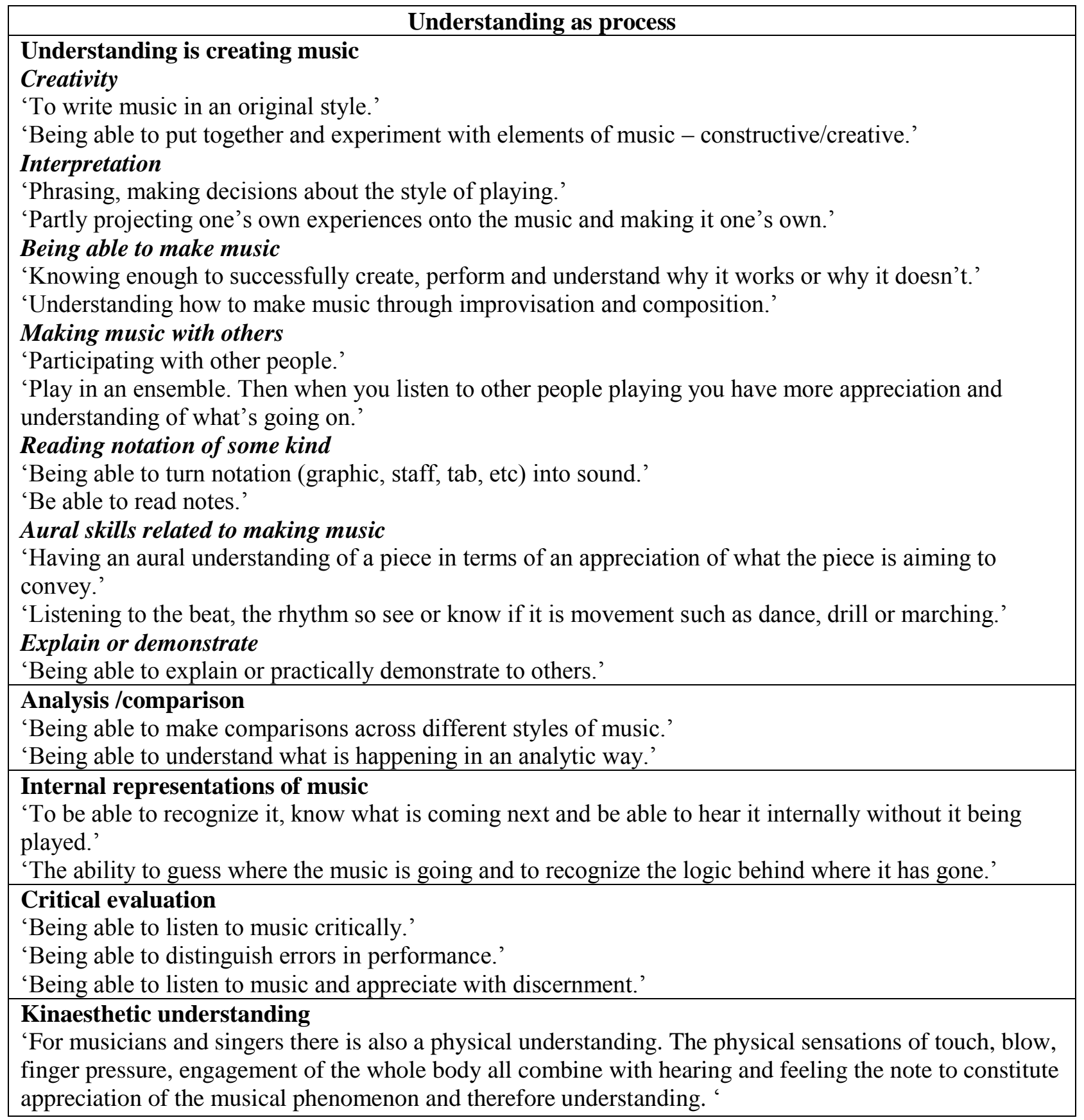


While the research was essentially qualitativein nature it was felt that it was important to provide an indication of the extent to which each theme was raised by each group in order to explore whether some themes emerged more strongly in particular groups. This was not intended to provide a statistical analysis of the data, but merely to give an indication of the ways in which different groups might perceive musical understanding. Table 3 sets out the number and percentage of participants responding in relation to each sub-theme. The most common responses overall were emotional understanding; understanding musical elements; being able to make music; and subjective appreciative evaluation of music. The responses least often generated included: critical evaluation; analysis/comparison; making music with others; kinaesthetic understanding; aural skills related to making music; internal representations of music and being able to explain or demonstrate. 
Table 3: Frequency of responses for each sub-theme across the whole sample

\begin{tabular}{|l|c|c|}
\hline & $\begin{array}{c}\text { Number of } \\
\text { individuals } \\
\text { responding in } \\
\text { each theme }\end{array}$ & Percentage \\
\hline Emotional understanding & 131 & $28 \%$ \\
\hline Understanding musical elements & 113 & $24 \%$ \\
\hline Creating music: Being able to make music & 109 & $23 \%$ \\
\hline Personal: Subjective appreciative evaluation & 102 & $22 \%$ \\
\hline Understanding musical elements: Musical structure & 93 & $20 \%$ \\
\hline Knowledge: Knowledge of genre & 92 & $20 \%$ \\
\hline Communication: Understanding the composers intentions & 75 & $16 \%$ \\
\hline Understanding musical elements: Identifying instrumentation & 71 & $15 \%$ \\
\hline Understanding as complex and multidimensional & 71 & $15 \%$ \\
\hline Creating music: Reading notation of some kind & 65 & $14 \%$ \\
\hline Knowledge: Knowledge of cultural context & 51 & $11 \%$ \\
\hline Personal: Personal/subjective understanding & 48 & $10 \%$ \\
\hline Communication: Understanding sound & 37 & $8 \%$ \\
\hline Knowledge: Knowledge of factual or historical aspects of music & 35 & $8 \%$ \\
\hline Communication: Music as a language & 33 & $7 \%$ \\
\hline Personal: Links with other elements of life & 31 & $7 \%$ \\
\hline Knowledge: The role and function of music in culture & 27 & $6 \%$ \\
\hline Creating music: Creativity & 26 & $6 \%$ \\
\hline Critical evaluation & 25 & $5 \%$ \\
\hline Analysis /comparison & 25 & $5 \%$ \\
\hline Creating music: Interpretation & 21 & $4 \%$ \\
\hline Creating music: Making music with others & 20 & $4 \%$ \\
\hline Creating music: Aural skills related to making music & 15 & $3 \%$ \\
\hline Kinaesthetic understanding & 13 & $3 \%$ \\
\hline Internal representations of music & 4 & $1 \%$ \\
\hline Creating music: Explain or demonstrate & 3 & $.6 \%$ \\
\hline & & \\
\hline
\end{tabular}

*Percentages do not sum to 100 as participants made more than one response

Further description was provided through adding the responses in each major sub-theme subsuming those from their sub-themes. Overall, participants made 1336 responses. Percentages were calculated based on the number of responses rather than the number of individuals responding in each theme. The greatest percentage of responses related to understanding musical elements (277 responses, 21\%) followed by creating music (259 responses, 19\%), knowledge about music (205 responses, 15\%), personal understandings (181 responses, $14 \%$ ), communication (145 responses, 11\%), emotional understanding (131 responses, 10\%), 
understanding as complex and multi-dimensional (71 responses, 5\%); and other understandings (67 responses, 5\%).

\section{Group differences.}

Unsurprisingly, the professional musicians made more reference to musical understanding being complex and multidimensional, with $33 \%$ of musicians making a response in relation to this theme. They also referred to more sub-themes than the other respondents with a mean number of responses of 4.16. They were also the group most likely to indicate that understanding related to understanding the composer's intentions $(25 \%)$. They, alongside the adults who were not actively engaged in music, gave the highest percentage of responses that understanding was emotional (43\%) and related to subjective appreciative evaluation (35\%) and personal subjective understanding (22\%). They also made many responses in relation to understanding musical elements (27\%), musical structure (30\%) and identifying instrumentation (27\%). They also generated numerous responses relating to knowledge of both genre (23\%) and knowledge of cultural context (23\%). Being able to create music through making it was also seen as important $(17 \%)$ as was analysis and comparison (11\%) (see Table 4). The adult amateur musicians made on average 3.00 responses. The focus of their responses was understanding musical elements and musical form along the emotional aspects of musical understanding and subjective appreciative evaluation. Surprisingly, the adult non-musicians made on average more responses than the adults involved in amateur music making (3.52). For them emotional understanding (43\%) was the focus followed by knowledge of genre (32\%) and subjective appreciative evaluation (31\%). They also acknowledged that understanding musical elements (28\%) and structure (20\%) were important (see Table 4). The young musicians on average made 2.27 responses. Their strongest responses were in relation to being able to make music (37\%), followed by understanding of 
musical elements (21\%), emotional understanding (20\%) and musical structure (19\%). Not surprisingly, the young people not actively engaged in music made the least number of responses (1.25). Their strongest responses related to being able to make music (28\%), reading notation of some kind (24\%) and understanding musical elements (20\%). In some sub-themes they made no response at all. 
Table 4: Generation of themes by number of participants

\begin{tabular}{|c|c|c|c|c|c|}
\hline Sub themes where applicable & $\begin{array}{l}\text { Professional } \\
\text { musicians } \\
(\mathbf{N}=113)\end{array}$ & $\begin{array}{l}\text { Adult } \\
\text { amateur } \\
\text { musicians } \\
(\mathrm{N}=60)\end{array}$ & $\begin{array}{l}\text { Adult } \\
\text { non- } \\
\text { musicians } \\
(\mathrm{N}=94)\end{array}$ & $\begin{array}{l}\begin{array}{l}\text { Young } \\
\text { musicians }\end{array} \\
(\mathrm{N}=92)\end{array}$ & $\begin{array}{l}\text { Young } \\
\text { non- } \\
\text { musicians } \\
(\mathrm{N}=104)\end{array}$ \\
\hline \multicolumn{6}{|c|}{ Musical understanding as complex and multidimensional } \\
\hline & $33 \%(37)$ & $20 \%(12)$ & $17 \%(16)$ & $7 \%(6)$ & \\
\hline \multicolumn{6}{|c|}{ Personal musical understanding in context } \\
\hline \multicolumn{6}{|c|}{ Communication } \\
\hline Music as a language & $12 \%(14)$ & $7 \%(4)$ & $10 \%(9)$ & $7 \%(6)$ & \\
\hline Understanding the composer's intentions & $25 \%(28)$ & $2 \%(1)$ & $14 \%(13)$ & $15 \%(14)$ & $18 \%(19)$ \\
\hline Understanding sound & $12 \%(13)$ & $8 \%(5)$ & $4 \%(4)$ & $15 \%(14)$ & $1 \%(1)$ \\
\hline \multicolumn{6}{|c|}{ Emotional understanding } \\
\hline & $43 \%(49)$ & $28 \%(17)$ & $43 \%(40)$ & $20 \%(18)$ & $5 \%(5)$ \\
\hline \multicolumn{6}{|c|}{ Personal understandings } \\
\hline Subjective understanding & $22 \%(25)$ & $18 \%(11)$ & $7 \%(7)$ & $3 \%(3)$ & $2 \%(2)$ \\
\hline Links with other elements of life & $10 \%(11)$ & $7 \%(4)$ & $14 \%(13)$ & & $3 \%(3)$ \\
\hline Subjective appreciative evaluation & $35 \%(40)$ & $27 \%(16)$ & $31 \%(29)$ & $15 \%(14)$ & $1 \%(1)$ \\
\hline \multicolumn{6}{|c|}{ Knowledge } \\
\hline Knowledge of facts about or history of music & $13 \%(15)$ & $3 \%(2)$ & $12 \%(11)$ & $2 \%(2)$ & $5 \%(5)$ \\
\hline Knowledge of genre & $23 \%(26)$ & $13 \%(8)$ & $32 \%(30)$ & $17 \%(16)$ & $12 \%(12)$ \\
\hline Knowledge of cultural context & $23 \%(26)$ & $7 \%(4)$ & $21 \%(20)$ & $1 \%(1)$ & \\
\hline The role and function of music in culture & $9 \%(10)$ & $5 \%(3)$ & $12 \%(11)$ & $3 \%(3)$ & \\
\hline \multicolumn{6}{|c|}{ Understanding musical elements } \\
\hline Undifferentiated & $27 \%(30)$ & $27 \%(16)$ & $28 \%(26)$ & $21 \%(19)$ & $20 \%(21)$ \\
\hline Musical structure & $30 \%(34)$ & $33 \%(20)$ & $20 \%(19)$ & $19 \%(17)$ & $2 \%(2)$ \\
\hline Identifying instrumentation & $27 \%(30)$ & $23 \%(14)$ & $17 \%(16)$ & $10 \%(9)$ & $2 \%(2)$ \\
\hline \multicolumn{6}{|c|}{ Musical understanding as process } \\
\hline \multicolumn{6}{|c|}{ Creating music } \\
\hline Creativity & $9 \%(10)$ & $5 \%(3)$ & $7 \%(7)$ & $3 \%(3)$ & $2 \%(2)$ \\
\hline Interpretation & $4 \%(4)$ & $8 \%(5)$ & $4 \%(4)$ & $8 \%(7)$ & \\
\hline Being able to make music & $17 \%(19)$ & $20 \%(12)$ & $7 \%(7)$ & $37 \%(34)$ & $28 \%(29)$ \\
\hline Making music with others & $6 \%(7)$ & $8 \%(5)$ & $4 \%(4)$ & $4 \%(4)$ & \\
\hline Reading notation of some kind & $4 \%(4)$ & $15 \%(9)$ & $14 \%(13)$ & $15 \%(14)$ & $24 \%(25)$ \\
\hline Aural skills related to making music & $9 \%(10)$ & $3 \%(2)$ & $2 \%(2)$ & $1 \%(1)$ & \\
\hline Explain or demonstrate & $3 \%(3)$ & & & & \\
\hline \multicolumn{6}{|c|}{ Other } \\
\hline Analysis /comparison & $11 \%(12)$ & $5 \%(3)$ & $9 \%(8)$ & $1 \%(1)$ & $1 \%(1)$ \\
\hline Internal representations of music & $1 \%(1)$ & $2 \%(1)$ & $1 \%(1)$ & $1 \%(1)$ & \\
\hline Critical evaluation & $6 \%(7)$ & $3 \%(2)$ & $15 \%(14)$ & $2 \%(2)$ & \\
\hline Kinaesthetic understanding & $4 \%(5)$ & $2 \%(1)$ & $7 \%(7)$ & & \\
\hline
\end{tabular}

When the analysis was undertaken in relation to the number of responses in each major sub-

theme there were differences in the responses for each group. The professional and amateur adult

musicians each indicated that understanding musical elements was the most important, the 
amateurs more than the professionals. For the adult non-musicians knowledge about music was central, while for both groups of young people it was creating music (non-musicians $43 \%$, musicians 30\%). Overall, personal understandings resonated more with the adults. Surprisingly the young musicians rated communication more highly than the professional musicians (see Table 5).

Table 5: Percentages of number of responses by group in each theme

\begin{tabular}{|c|c|c|c|c|c|}
\hline $\begin{array}{l}\text { Percentage of responses in relation to each main } \\
\text { theme }\end{array}$ & $\begin{array}{l}\text { Professional } \\
\text { musicians } \\
\text { Responses = } \\
470\end{array}$ & $\begin{array}{l}\text { Adult } \\
\text { amateur } \\
\text { musicians } \\
\text { Responses } \\
=180\end{array}$ & $\begin{array}{l}\text { Adult } \\
\text { non- } \\
\text { musicians } \\
\text { Responses } \\
=331 \\
\end{array}$ & $\begin{array}{l}\text { Young } \\
\text { musicians } \\
\text { Responses } \\
=209 \\
\end{array}$ & $\begin{array}{l}\text { Young } \\
\text { non- } \\
\text { musicians } \\
\text { Responses } \\
=130\end{array}$ \\
\hline Complex & $8 \%(37)$ & $7 \%(12)$ & $5 \%(16)$ & $3 \%(6)$ & \\
\hline \multicolumn{6}{|c|}{ Personal musical understanding in context } \\
\hline Communication & $12 \%(55)$ & $6 \%(10)$ & $8 \%(26)$ & $16 \%(34)$ & $15 \%(20)$ \\
\hline Emotional & $10 \%(49)$ & $9 \%(17)$ & $12 \%(40)$ & $9 \%(18)$ & $4 \%(5)$ \\
\hline Personal & $16 \%(76)$ & $17 \%(31)$ & $15 \%(49)$ & $8 \%(17)$ & $5 \%(6)$ \\
\hline Knowledge about music & $16 \%(77)$ & $9 \%(17)$ & $22 \%(72)$ & $11 \%(22)$ & $13 \%(17)$ \\
\hline Musical elements & $20 \%(94)$ & $28 \%(50)$ & $18 \%(61)$ & $21 \%(45)$ & $19 \%(25)$ \\
\hline \multicolumn{6}{|c|}{ Musical understanding as process } \\
\hline Creating music & $12 \%(57)$ & $20 \%(36)$ & $11 \%(37)$ & $30 \%(63)$ & $43 \%(56)$ \\
\hline Other & $5 \%(25)$ & $4 \%(7)$ & $9 \%(30)$ & $2 \%(4)$ & $1 \%(1)$ \\
\hline \multicolumn{6}{|c|}{ Number of responses } \\
\hline Number of responses & 470 & 180 & 331 & 209 & 130 \\
\hline Mean & 4.16 & 3 & 3.52 & 2.27 & 1.25 \\
\hline
\end{tabular}

*Percentages have been rounded to the nearest whole number so may not sum to 100

*Numbers in brackets refer to number of responses

\section{How is Musical Understanding Developed?}

In the same way that people recognized the complexity of musical understanding, they recognized that developing musical understanding could be undertaken through multiple activities:

'Listening, performing, discussing, composing.'

'Any musical activities help you to understand music, even if you don't formally study it.' 
'Listening to various genres and styles, attending concerts, reading articles, books, watching musical activities, practising an instrument, having lessons.'

The same two overarching themes emerged as in relation to the nature of understanding: personal understanding in context and understanding as process. For personal understanding in context three sub-themes emerged: understanding through love and enjoyment of music; through physical responses to music;and through emotional engagement. For understanding through process five sub-themes emerged: understanding through analytic processes; through active engagement with music; through education or guidance in formal or informal contexts (including feedback); through exposure to music (including through family and friends); and through listening. Example quotations and the sub-themes for each theme are set out in Table 6 . 
Table 6: Themes relating to the development of understanding

\begin{tabular}{|c|}
\hline $\begin{array}{l}\text { Personal musical understanding in context } \\
\end{array}$ \\
\hline $\begin{array}{l}\text { Understanding through love and enjoyment of music } \\
\text { 'Loving music and actively engaging in musical activities.' } \\
\text { 'Everything that when you hear it you enjoy it and it moves you positively.' } \\
\text { 'Enjoying music, the international language.' }\end{array}$ \\
\hline $\begin{array}{l}\text { Understanding through physical responses to music } \\
\text { 'Physical responses like dance.' } \\
\text { 'Listening to it, feeling the vibrations and the rhythms.' }\end{array}$ \\
\hline $\begin{array}{l}\text { Understanding through emotional engagement } \\
\text { 'Wanting to get in touch with your emotions. Connecting with other people's emotions.' } \\
\text { 'We understand music through feeling, instinctively, and by relating it to our past musical experiences.' }\end{array}$ \\
\hline Musical understanding as process \\
\hline $\begin{array}{l}\text { Understanding through analytic processes } \\
\text { 'Examining individual elements/genres and why and how they work.' } \\
\text { 'Dissecting and analyzing how a piece of music was put together.' } \\
\text { 'Understanding through engagement in discussions } \\
\text { 'Talking to other musicians and discussing.' } \\
\text { 'Discussion with peer groups and family.' }\end{array}$ \\
\hline $\begin{array}{l}\text { Understanding through active engagement with making music } \\
\text { 'Being able to take part in musical activities.' } \\
\text { 'Engagement in listening, composing, performing, improvising, appreciation of music.' } \\
\text { 'Practise it over and over again.' } \\
\text { Musical expression and communication } \\
\text { 'Playing or singing with sensitive musical expression and communication.' } \\
\text { 'Being able to perform music musically.' } \\
\text { 'Enderstanding through experimentation } \\
\text { Understanding through reflection } \\
\text { 'Reflection (watching musicians).' } \\
\text { 'Reflecting on your own efforts at performance.' } \\
\text { 'Researching and thinking.' }\end{array}$ \\
\hline $\begin{array}{l}\text { Understanding through education or guidance in formal or informal contexts (including feedback) } \\
\text { 'Learning from others especially rehearsal/performance with professional /talented musicians.' } \\
\text { 'High level formal instruction undoubtedly plays a part in fostering a truly deep and rich musical } \\
\text { understanding at a sophisticated level. Even a basic musical literacy (in Western culture anyway) requires } \\
\text { some degree of systematic instruction/ learning.' } \\
\text { 'A fuller understanding of any kind of music or musical tradition requires a degree of guidance or } \\
\text { initiation. In other words we have to be taught to understand and appreciate music even if we teach } \\
\text { ourselves by reading books or CD inserts or follow a teach yourself course. Like language music is } \\
\text { something we have to learn to appreciate and enjoy.' } \\
\text { 'Learn through receiving feedback.' } \\
\text { 'Music lessons.' } \\
\text { Understanding through teaching } \\
\text { 'Teaching the requirements of the National Curriculum has forced me to widen my knowledge about } \\
\text { world music.' }\end{array}$ \\
\hline $\begin{array}{l}\text { Understanding through exposure to music (including through family and friends) } \\
\text { 'Enculteration - growing up in a rich musical environment.' } \\
\text { 'A vast array of stimuli, individual, group music making, media, friends.' }\end{array}$ \\
\hline
\end{tabular}


Early years

'As with all languages I believe this is best learnt when very young and this is most successful in actively musical households where the family influence is strong.'

'Being exposed to it from an early age.'

Understanding through listening

'Listening to a wide range of music recorded and live.'

'Listening - there is no substitute.'

'Being able to focus one's attention on sound.'

Listening to a wide range of music/ being open eared

'Listening and appreciating different musics.'

'By exposing yourself to as broad a pallet of music as possible.'

'Listening to different types of music, allowing yourself to be exposed to new types, being open minded about music.'

Music learning through other media

'Internet.'

'Linking with other media or events (Shakespeare and music of late Renaissance/early Baroque).

'Reading about it.'

Table 7 provides information about the percentage of individuals responding in each sub-

theme,revealing that overall the highest percentage of individuals responding was in relation to

understanding through listening (63\%); followed by active engagement with music (58\%);

education or guidance in formal or informal contexts (including feedback) (30\%); love and

enjoyment of music (17\%); listening to a wide range of music (being open eared) (13\%); and

through exposure to music (including through family and friends) (10\%) (see Table 7). As some

individuals made more than one response the percentages do not total to $100 \%$. 


\section{Table 7: Generation of themes}

\begin{tabular}{|l|l|l|}
\hline Understanding through: & $\begin{array}{l}\text { Number of } \\
\text { individuals } \\
\text { responding } \\
\text { in each } \\
\text { theme }\end{array}$ & Percentage \\
\hline Listening & 295 & $63 \%$ \\
\hline Active engagement with making music & 269 & $58 \%$ \\
\hline Education or guidance in formal or informal contexts (including feedback) & 138 & $30 \%$ \\
\hline Love and enjoyment of music & 77 & $17 \%$ \\
\hline Listening - Listening to a wide range of music/ being open eared & 61 & $13 \%$ \\
\hline Listening - exposure to music (including through family and friends) & 46 & $10 \%$ \\
\hline Listening - Music learning through other media & 40 & $9 \%$ \\
\hline Analytic processes - Understanding through engagement in discussions & 36 & $8 \%$ \\
\hline $\begin{array}{l}\text { Active engagement with making music - Understanding through } \\
\text { experimentation }\end{array}$ & 36 & $8 \%$ \\
\hline Analytic processes & & \\
\hline Emotional engagement & 34 & $7 \%$ \\
\hline Active engagement with making music - Understanding through reflection & 23 & $5 \%$ \\
\hline Listening - Early years & 19 & $4 \%$ \\
\hline Understanding through physical responses to music & 17 & $4 \%$ \\
\hline Musical expression and communication & 12 & $3 \%$ \\
\hline Understanding through teaching others & 10 & $2 \%$ \\
\hline
\end{tabular}

*Percentages do not sum to 100 as respondents made responses in more than one theme

A further analysis was undertaken which added the responses in each major theme, subsuming those from the sub-themes. Overall, participants made 1119 responses. The percentages for this analysis were calculated based on the number of responses rather than the number of individuals in the sample. The greatest percentage of responses related to listening (396 responses, 35\%) and active engagement with music (334 responses, 30\%) followed by education or guidance in formal or informal settings (144 responses, 13\%), love and enjoyment (77 responses, 7\%), analytic processes (70 responses, $6 \%$ ), exposure to music (63 responses, $6 \%$ ), emotional engagement (23 responses, $2 \%$ ) and physical responses (12 responses, $1 \%$ ).

\section{Group differences.}

The professional musicians on average made the most responses (3.28). For them understanding was achieved mainly through listening (75\%) and active engagement with making music (74\%). 
Education or guidance received support from 27\%; followed by experimentation (21\%); and love and enjoyment (20\%).The adult amateur musicians on average made 2.15 responses. The highest percentage of them responded in relation to active engagement with music (58\%); listening (38\%); education (30\%); love and enjoyment (18\%); and exposure (17\%).Adults not actively engaged in music made on average 2.5 responses and indicated that understanding was mainly acquired through listening (67\%); active engagement with music (42\%); listening to a wide range of music - being open eared (28\%); education (25\%); through other media (19\%); and through love and enjoyment (18\%).The young musicians made on average 2.42 responses and indicated that active engagement was the key to understanding (79\%) followed by listening (66\%); education (36\%); love and enjoyment (15\%); and listening to a wide range of music - being open eared (10\%). The young people not actively engaged with music made on average 1.46 responses and reported that understanding was acquired through listening (61\%); active engagement with music making (37\%); education (29\%); and love and enjoyment of music (10\%)(see Table 8). 
Table 8: Generation of themes by groups

\begin{tabular}{|c|c|c|c|c|c|}
\hline & $\begin{array}{l}\text { Professional } \\
\text { musicians } \\
\mathrm{N}-113\end{array}$ & $\begin{array}{l}\text { Adult } \\
\text { amateur } \\
\text { musicians } \\
\mathrm{N}=60\end{array}$ & $\begin{array}{l}\begin{array}{l}\text { Adult non- } \\
\text { musicians }\end{array} \\
\mathrm{N}=94\end{array}$ & $\begin{array}{l}\begin{array}{l}\text { Young } \\
\text { musicians }\end{array} \\
\mathrm{N}=92\end{array}$ & $\begin{array}{l}\text { Young } \\
\text { non- } \\
\text { musicians } \\
\mathrm{N}=104\end{array}$ \\
\hline \multicolumn{6}{|c|}{ Personal musical understanding in context } \\
\hline \multicolumn{6}{|c|}{ Understanding through love and enjoyment of music } \\
\hline & $20 \%(23)$ & $18 \%(11)$ & $18 \%(17)$ & $15 \%(14)$ & $10 \%(10)$ \\
\hline \multicolumn{6}{|c|}{ Understanding through physical responses to music } \\
\hline & $4 \%(5)$ & & $5 \%(5)$ & $1 \%(1)$ & \\
\hline \multicolumn{6}{|c|}{ Understanding through emotional engagement } \\
\hline & $7 \%(8 \mid)$ & & $12 \%(11)$ & $3 \%(3)$ & \\
\hline \multicolumn{6}{|c|}{ Musical understanding through process } \\
\hline \multicolumn{6}{|c|}{ Understanding through analytic processes } \\
\hline Undifferentiated & $13 \%(15)$ & $10 \%(6)$ & $7 \%(7)$ & $7 \%(6)$ & \\
\hline $\begin{array}{l}\text { Understanding through } \\
\text { engagement in discussions }\end{array}$ & $16 \%(18)$ & $10 \%(6)$ & $4 \%(4)$ & $8 \%(7)$ & $1 \%(1)$ \\
\hline \multicolumn{6}{|c|}{ Understanding through active engagement with making music } \\
\hline Undifferentiated & $74 \%(83)$ & $58 \%(35)$ & $42 \%(39)$ & $79 \%(73)$ & $37 \%(38)$ \\
\hline $\begin{array}{l}\text { Musical expression and } \\
\text { communication }\end{array}$ & $5 \%(6)$ & $2 \%(1)$ & $1 \%(1)$ & $2 \%(2)$ & \\
\hline $\begin{array}{l}\text { Understanding through } \\
\text { experimentation }\end{array}$ & $21 \%(24)$ & $2 \%(1)$ & $4 \%(4)$ & $5 \%(5)$ & $2 \%(2)$ \\
\hline $\begin{array}{l}\text { Understanding through } \\
\text { reflection }\end{array}$ & $10 \%(11)$ & $3 \%(2)$ & $1 \%(1)$ & $5 \%(5)$ & \\
\hline \multicolumn{6}{|c|}{$\begin{array}{c}\text { Understanding through education or guidance in formal or informal contexts (including } \\
\text { feedback) }\end{array}$} \\
\hline Undifferentiated & $27 \%(30)$ & $35 \%(21)$ & $25 \%(23)$ & $36 \%(33)$ & $29 \%(30)$ \\
\hline $\begin{array}{l}\text { Understanding through } \\
\text { teaching others }\end{array}$ & $4 \%(5)$ & $2 \%(1)$ & & & \\
\hline \multicolumn{6}{|c|}{ Understanding through exposure to music (including through family and friends) } \\
\hline Undifferentiated & $16 \%(18)$ & $17 \%(10)$ & $13 \%(12)$ & $4 \%(4)$ & \\
\hline Early years & $\begin{array}{l}8 \\
7 \% \\
\end{array}$ & $\begin{array}{l}4 \\
7 \% \\
\end{array}$ & $\begin{array}{l}4 \\
4 \% \\
\end{array}$ & & \\
\hline \multicolumn{6}{|c|}{ Understanding through listening } \\
\hline Undifferentiated & $75 \%(85)$ & $38 \%(23)$ & $67 \%(63)$ & $66 \%(61)$ & $61 \%(63)$ \\
\hline $\begin{array}{l}\text { Listening to a wide range } \\
\text { of music/ being open eared }\end{array}$ & $14 \%(16)$ & $10 \%(6)$ & $28 \%(26)$ & $10 \%(9)$ & $4 \%(4)$ \\
\hline $\begin{array}{l}\text { Music learning through } \\
\text { other media }\end{array}$ & $14 \%(16)$ & $3 \%(2)$ & $19 \%(18)$ & & $4 \%(4)$ \\
\hline Total responses & 371 & 129 & 235 & 223 & 152 \\
\hline $\begin{array}{l}\text { Mean number of } \\
\text { responses }\end{array}$ & 3.28 & 2.15 & 2.5 & 2.42 & 1.46 \\
\hline
\end{tabular}

When the analysis was undertaken in relation to the number of responses in each major sub-

theme rather than the number of individuals responding in that theme there were differences in 
the responses for each group. The most striking differences were between the musicians who gave stronger responses in relation to understanding through active music making and the nonmusicians who gave stronger responses in relation to listening (see Table 9).

Table 9: Percentages of number of responses to main themes by group

\begin{tabular}{|c|c|c|c|c|c|}
\hline & $\begin{array}{l}\text { Professional } \\
\text { musicians } \\
\text { Number of } \\
\text { responses = } \\
371\end{array}$ & $\begin{array}{l}\text { Adult } \\
\text { amateur } \\
\text { musicians } \\
\text { Number } \\
\text { of } \\
\text { responses } \\
=129\end{array}$ & $\begin{array}{l}\text { Adult non- } \\
\text { musicians } \\
\text { Number of } \\
\text { responses = } \\
107\end{array}$ & $\begin{array}{l}\text { Young } \\
\text { musicians } \\
\text { Number } \\
\text { of } \\
\text { responses } \\
=223\end{array}$ & $\begin{array}{l}\text { Young non- } \\
\text { musicians } \\
\text { Number of } \\
\text { responses = } \\
152\end{array}$ \\
\hline \multicolumn{6}{|c|}{ Musical understanding in context } \\
\hline $\begin{array}{l}\text { Understanding through love and } \\
\text { enjoyment of music }\end{array}$ & $6 \%(23)$ & $9 \%(11)$ & $7 \%(17)$ & $6 \%(14)$ & $7 \%(10)$ \\
\hline $\begin{array}{l}\text { Understanding through physical } \\
\text { responses to music }\end{array}$ & $1 \%(5)$ & & $2 \%(5)$ & $0.4 \%(1)$ & \\
\hline $\begin{array}{l}\text { Understanding through emotional } \\
\text { engagement }\end{array}$ & $2 \%(8 \mid)$ & & $5 \%(11)$ & $1 \%(3)$ & \\
\hline \multicolumn{6}{|c|}{ Musical understanding as process } \\
\hline $\begin{array}{l}\text { Understanding through analytic } \\
\text { processes }\end{array}$ & $9 \%(33)$ & $9 \%(12)$ & $5 \%(13)$ & $6 \%(13)$ & $0.6 \%(1)$ \\
\hline $\begin{array}{l}\text { Understanding through active } \\
\text { engagement with making music }\end{array}$ & $33 \%(124)$ & $30 \%(39)$ & $19 \%(45)$ & $38 \%(85)$ & $26 \%(40)$ \\
\hline $\begin{array}{l}\text { Understanding through education or } \\
\text { guidance in formal or informal } \\
\text { contexts (including feedback) }\end{array}$ & $9 \%(35)$ & $17 \%(22)$ & $10 \%(23)$ & $15 \%(33)$ & $20 \%(30)$ \\
\hline $\begin{array}{l}\text { Understanding through exposure to } \\
\text { music (including through family and } \\
\text { friends) }\end{array}$ & $7 \%(26)$ & $11 \%(14)$ & $7 \%(16)$ & $1 \%(4)$ & \\
\hline Understanding through listening & $32 \%(117)$ & $24 \%(31)$ & $45 \%(107)$ & $31 \%(70)$ & $47 \%(71)$ \\
\hline Total responses & 371 & 129 & 235 & 223 & 152 \\
\hline Mean number of responses & 3.28 & 2.15 & 2.5 & 2.42 & 1.46 \\
\hline
\end{tabular}

*Percentages may not add to 100 as they have been rounded to the nearest whole number

\section{Discussion}

There are limitations to this research. As with all qualitative research there are issues relating to the extent to which the findings can be generalised. The large sample, made possible by the specific methodology adopted, does provide some basis for generalising the findings to other 
populations.However, the findings reflect the nature of the research method adopted, particularly as the numeric data included is at a descriptive and therefore indicative level. The methodology, while enabling access to strongly held and personal perceptions, relied on the generation of those ideas with no prompts. Individuals may have had other conceptions which they could not bring to mind at that point in time. A further study using rating scales to which respondents indicate their level of agreement to statements is indicated. This would also enable complex statistical analysis.

Across the whole sample musical understanding was mainly viewed as relating to musical elements and being able to create or recreate music, although there was also a substantial number of respondents who indicated that understanding related to knowledge about music, personal understandings, communication and emotional understanding. Examination of the differences between groups, although no statistical analysis was undertaken,suggested that the professional musicians held the most complex and detailed conceptions and that the young people not actively engaged in music beyond the school curriculum the least. The professionals, more than the other groups, emphasised understanding the composers' intentions, presumably because this is a focus of their daily work and is also a product of their training. The adults who were not actively engaged in making music emphasised the importance of knowledge about music, while all of the adults gave more responses in relation to personal understandings. In contrast, the young people, whether actively engaged in making music or not, emphasised the importance of communication and creating and re-creating music. The adult amateur musicians emphasised understanding in terms of musical elements. These differences suggest that conceptions of understanding are based on individuals' differing experiences with music and music education. 
There was greater agreement on how musical understanding is achieved. Overwhelmingly it was seen to develop through active engagement in making music or listening to music. The emphasis given to each of these varied with those who were actively engaged in making music giving greater emphasis to that, while those who were not gave greater emphasis to listening.

Overall, the research showed that music can be and is understood in a variety of ways. There is overlap between the types of engagement which may lead to understanding as there is between the different kinds of understanding. Engagement with music in any form is likely to increase understanding in some way. The key issue that needs to be considered by music educators is the kind of understandingsthat music education should be developing. It is arguable that all of them are relevant and important. What has tended to be neglected in music education is recognition and understanding of the emotional impact of music, the extent to which it can change moods and engender emotional responses and the way that personal understandings develop. As music has increasingly become accessible to everyone at any time and there is compelling evidence to suggest that individuals use their personal understandings to manipulate moods and emotions these elements should perhaps be considered as part of music education.

In the teaching of music whether in classrooms or instrumental tuition the focus is mainly on acquiring skills which facilitate participation in music or developing an intellectual understanding of it. There is little emphasis on music as communication and acknowledgement of the wider benefits it can have throughout life in relation to general well-being (see Clift et al., 2010; Hallam et al., 2014). The evidence of the beneficial effects of music in the long term make a strong case for one element of music education being on engendering motivation to continue active engagement with music throughout the lifespan. 
Figure 1 provides a representation of the findings synthesising the ways in which musical understanding is perceived to be acquired alongside the different types of understanding identified. Many of the elements of the model are similar to those proposed by Wiggins (2015) who sets out dimensions and metadimensions of musical experience. The models differ in that the centre of her model includes musical elements with the metadimensions, for instance, affective qualities, genre, historical context, encircling these. The model proposed here places love and enjoyment at the centre. Of course this is controversial, but education provides a foundation for learning throughout life. If a love of music is not engendered prior to an individual's transition to adulthood it is unlikely that any further engagement with music will follow. Promoting love and enjoyment of music should perhaps therefore take its place alongside other educational aims. This does not preclude the pursuit of high levels of attainment and deep understanding of music in all its forms. Indeed, where the quality of learning and its outcomes are high in any activity, participants derive greater enjoyment, providing that the learning environment is supportive and positively framed. Positive emotional experiences in music lessons will lead to greater enthusiasm and motivation which in turn heighten levels of engagement, enhance knowledge and skills, and promote the attainment of higher levels of expertise. Being able to engage with more complex music and having greater composition skills increases the level of challenge and pleasure when goals are attained. An emphasis on self expression and the emotional elements of music may also facilitate the development of a musical identity. There are also benefits to the teacher in that well motivated students are easier and more rewarding to teach. 


\section{Figure 1. Promoting Musical Understanding}

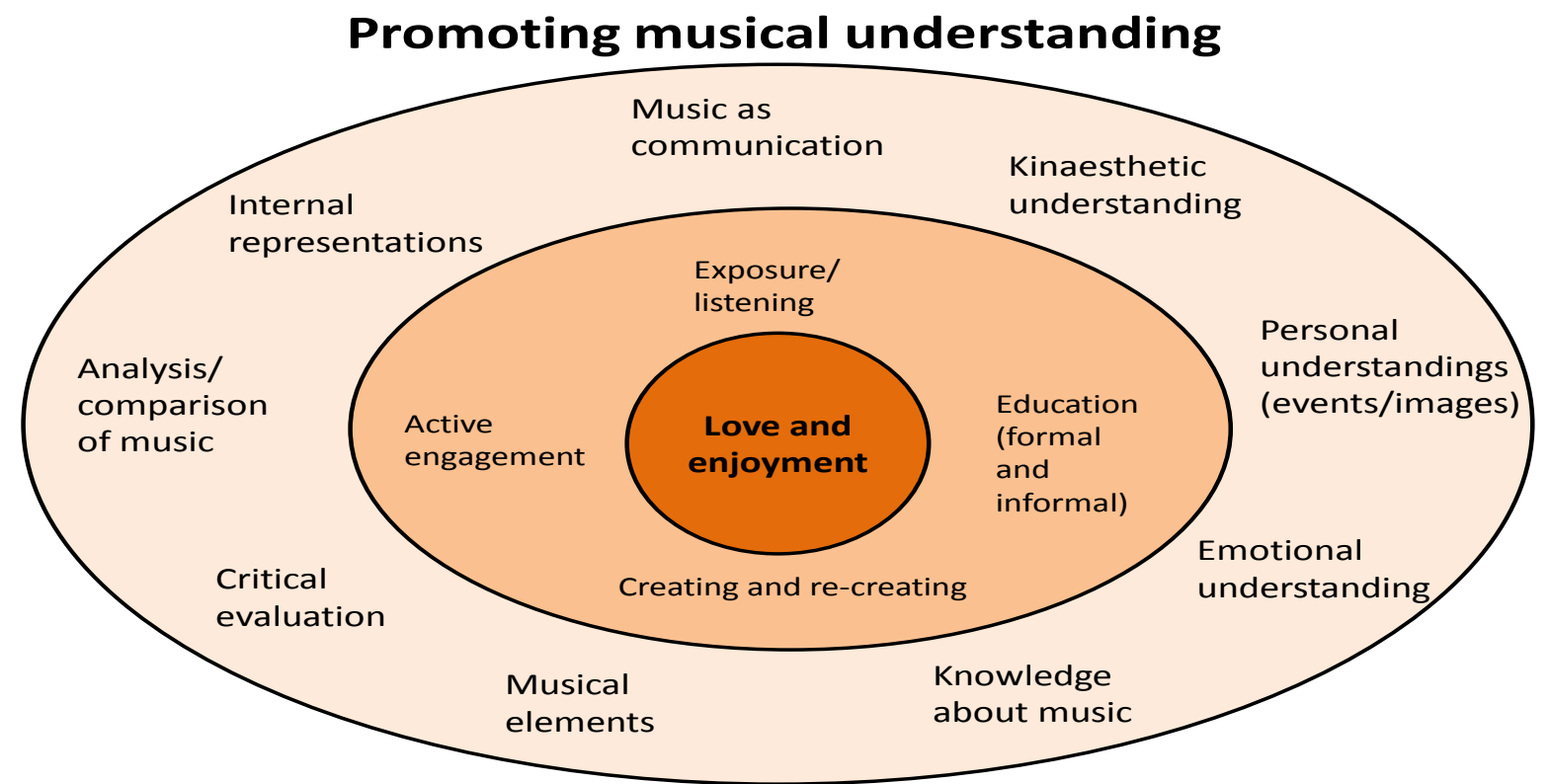

\section{References}

Altenmuller, E.O. (2003). How many music centres are in the brain? In I. Peretz\& R. Zatorre

(Eds.), The cognitive neuroscience of music (pp. 346-356). Oxford, UK: Oxford University

Press.

Anderson, R.C. (1984). Some reflections on the acquisition of knowledge,Educational

Researcher,13(9), 5-10.

Bamberger, J. (2003). The development of intuitive musical understanding: Anatural experiment. Psychology of Music, 31(1), 7-36.

Barrett, M. (1997). Invented notations: Aview of young children's musical thinking. Research Studies in Music Education, 8,2-14. 
Bartel, L. (2002). Meaning and understanding in music. In B. Henley \& T.W. Goolsby

(Eds.),Musical understanding: Perspectives in theory and practice(pp. 51-70). The Canadian

Music Educators Association, Victoria, British Columbia.

Bartlett, D.L. (1996). Physiological responses to music and sound stimuli. In D.A. Hodges

(Ed.),Handbook of music psychology. San Antonio, TX: IMR Press.

Behne, K.E. (1997). The development of 'Musikerleben' in adolescence: How and why young people listen to music. In I. Deliege\& J.A. Sloboda (Eds.),Perception and cognition of music. Hove, UK: Psychology Press.

Biggs, J. (1979) Individual Differences in Study Processes and the Quality of Learning Outcomes Higher Education, 8 (4), 381-394

Bloom, B.S. (1956) Taxonomy of educational objectives: The classification of educational goals, 1st ed.Harlow, Essex, England: Longman Group

Bruner, J. (1966) Toward a theory of instruction. New York, NY: W.W. Norton.

Budd, M. (1985). Understanding music. Proceedings of the Aristotelian Society, 59, 233-248.

Burnard, P. (2000). Examining experiential differences between improvisation and composition in children's music-making. British Journal of Music Education,17(3), 227-245.

Campbell, P.S. (1998). The musical cultures of children. Research Studies in Music Education, $11,42-51$.

Campbell, P.S. (2005). Deep listening to the musical world. Music Educators Journal, September, 30-36.

Clift, S., Nicol, J., Raisbeck, M., Whitmore, C., \& Morrison, I. (2010). Group singing, wellbeing and health:A systematic mapping of research evidence. Folkestone, UK: Sidney De Haan Research Centre for Arts and Health, Canterbury Christ Church University, UK. 
Colwell, R \& Abrahams, F. (1991) Edwin Gordon's contribution: An appraisal. The quarterly philosophy in music education, 11(1-2), 19-36.

Cooper, P.,\& McIntyre, D. (1993). Commonality in teachers' and pupils' perceptions of effective classroom learning. British Journal of Educational Psychology,63, 381-399.

Davidson, L., Scripp, L., \& Welsh, P. (1988). “Happy Birthday”: Evidence for conflicts of perceptual knowledge and conceptual understanding. Journal of Aesthetic Education, 22(1), 6574.

Davies, S. (1994).Musical meaning. Ithaca, New York: Cornell University Press.

DeNora, T. (2000). Music in everyday life. Cambridge, UK: Cambridge University Press.

Dibben, N. (2001). What do we hear, when we hear music?: Music perception and musical material. MusicaeScienticae, 5(2), 161-194

Dowling, W.J. (1988). Tonal structure and children's early learning of music. In J.A. Sloboda (Ed.),Generative processes in music: The psychology of performance, improvisation and composition (pp. 113-128). Oxford, UK: Clarendon Press.

Dowling, W.J. (1999). The development of music perception and cognition. In D. Deutsch (Ed.),The psychology of music, (2nd ed., pp. 603-625). London, UK: Academic Press.

Elliott, D. (1995). Music matters: A new philosophy of music education. New York, NY: Oxford University Press.

Elliot, D.J. (2005). Musical understanding, musical works, and emotional expression: Implications for education.Educational Philosophy and Theory, 37(1), 93-103.

Ferguson, A.R.,Carbonneau, M.R., \& Chambliss, C. (1994). Effects of positive and negative music on performance of a karate drill. Perceptual Motor Skills,78, 1217-1218. 
Fiske, H.E. (2008). Understanding musical understanding: The philosophy, and sociology of the musical experience. Lewiston, NY: The Edwin Mellen Press.

Gabrielsson, A. (1993). Emotion and music. Newsletter of the European Society for the Cognitive Sciences of Music,4, 4-9.

Gabrielsson, A. (2001). Emotions in strong experiences with music. In P.N. Juslin\& J.A.

Sloboda (Eds.),Music and emotion: Theory and research (pp. 431-452). Oxford, UK: Oxford University Press.

Gagne, R. (1985)The Conditions of Learning and Theory of Instruction. Holt, Rinehart and Winston, Inc., Florida-ABD, 4th edition

Gardner, H. (1999). Intelligence reframed: Multiple intelligences for the 21 st century. New York, NY: Basic Books.

Glover, J. (1990). Understanding children's musical understanding. British Journal of Music Education, 7(3), 257-262.

Gordon, E.E. (1993). Learning sequences in music: Skills, contents, and patterns. A music learning theory. Chicago, IL: GIA Publications.

Gromko, J. (1994). Children's invented notations as measures of musical understanding. Psychology of Music, 22, 136-147.

Haack, P. (1990). Beyond objectivity - the feeling factor in listening. Music Educators Journal, December, 28-32.

Hallam, S., Creech, A., Varvarigou, M., McQueen, H.,\& Gaunt, H. (2014). Does active engagement in community music support quality of life in older people? Arts and Health,6(2), $101-116$. 
Hallam, S., Shaw, J.,\&Rhamie, J. (2006). Evaluation of the primary behaviour and attendance pilot. Research report. London, UK: Department for Education and Skills.

Hargreaves, D.J. (1986). The developmental psychology of music. Cambridge, UK: Cambridge University Press.

Knieter, G.L. (1971). The nature of aesthetic education. In Toward an Aesthetic Education.

Washington, DC: Music Educators National Conference.

Lakoff, G.,\& Johnson, M. (1999) Philosophy in the flesh: The embodied mind and its challenge to Western thought. New York, NY: Basic.

Lamont, A., \& Cross, I. (1994). Children's cognitive representations of musical pitch. Music Perception, 12(1), 27-55.

LeBlanc, A. (1982). An interactive theory of musical preference. Journal of Music Therapy, $19,28-45$.

Lipscomb, S.D. (1996). The cognitive organization of musical sound. In D. A. Hodges (Ed.),Handbook of music psychology (2nd ed., pp. 135-175). San Antonio, TX: IMR Press. Meyer, L.B. (1956). Emotion and meaning in music. Chicago, IL: Chicago University Press. Mursell, J.L. (1937).The psychology of music. New York, NY: W.W. Norton.

North, A.C., Hrgreaves, D.J., \& O’Neill, S.A. (2000) The importance of music to adolescents, British Journal of Educational Psychology, 70(2), 255-272.

Ogata, S. (1995). Human EEG responses to classical music and simulated white noise: Effects of a musical loudness component on consciousness. Perceptual and Motor Skills, 80, 779-790.

Petrides, K.V.,\&Furnham, A. (2001). Trait emotional intelligence: Psychometric investigation with reference to established trait taxonomies.European Journal of Personality, 15, 425-448. Piaget, J. (1973).To understand is to invent: The future of education. New York, NY:Grossman. 
Reimer, B. (1970). A philosophy of music education. Upper Saddle River, NJ: Prentice Hall.

Rogoff, B. (1990).The cultural nature of human development. New York, NY: Oxford University Press.

Ross, M. (1984).The aesthetic impulse. Oxford, UK: Pergamon Press.

Saarikallio, S.,\&Erkkila, J. (2007). The role of music in adolescent's mood regulations.

Psychology of Music,35(1), 88-109.

Seashore, C.E. (1919).The psychology of musical talent. New York, NY: Silver Burdett.Serafine, M.L. (1988).Music as cognition: The development of thought in sound. New York, NY: Oxford University Press.

Sloboda, J.A.,\& O’Neill, S.A. (2002). Emotions in everyday listening to music. In P. N. Juslin\& J. A. Sloboda (Eds.), Music and emotion: Theory and research (pp. 415-430). Oxford, UK:

Oxford University Press.

Sloboda, J.A., O’Neill, S.A., \&Ivaldi, A. (2001). Functions of music in everyday life: An exploratory study using the experience sampling method. Musicae Scientiae, 5, 9-32.

Swanwick, K.,\& Franca, C.C. (1999). Composing, performing and audience-listening as indicators of musical understanding.British Journal of Music Education,16(1), 5-20.

Swanwick, K., \& Tillman, J. (1986). The sequence of musical development: A study of children's composition. BritishJournal of Music Education,3(3), 305-339.

Tanner, M. (1985). Understanding music. Proceedings of the Aristotelian Society, 59, 215-232.

Tesch, R. (1990).Qualitative research: Analysis types and software tools. Hampshire, UK: The Falmer Press.

Trehub, S.E., Hill, D.S., \&Kamenetsky, S.B. (1997). Parents'sung performances for infants. Canadian Journal of Experimental Psychology, 51, 385-396. 
Vanderark, S.D.,\& Ely, D. (1993). Cortisol, biochemical and galvanic skin responses to music stimuli of different preference values by college students in biology and music. Perceptual and Motor Skills, 77, 227-234.

Vygotsky, L.S. (1978).Mind in society: The development of higher psychological processes (Ed \&translatation, M. Cole, V. John-Steiner, S. Scribner \& E. Souberman). Cambridge,MA:

Harvard University.

Wenger, E. (1998).Communities of practice: Learning, meaning and identity. New York, NY:

Cambridge University.

Wertsch, J.V. (Ed.). (1985).Culture, communication and cognition: Vygotskian perspectives.

Cambridge, UK: Cambridge University Press.

Wiggins, J. (2015).Teaching for musical understanding. Oxford, UK: Oxford University Press. Woodford, P.G. (1996) Evaluating Edwin Gordon's Music Learning theory from a critical thinking perspective, Philosophy of Music Education Review, 4(2), 83-95.

Zenker, R. (2002). The dynamic and complex nature of musical understanding. In B. Henley \& T.W. Goolsby (Eds.),Musical understanding: Perspectives in theory and practice(pp. 27-50). The Canadian Music Educators Association, Victoria, British Columbia 